\title{
Regional Emissions of Anthropogenic Halocarbons Derived from Continuous Measurements of Ambient Air in Switzerland
}

\author{
Brigitte Buchmann*, Konrad Stemmler, and Stefan Reimann
}

\begin{abstract}
Man-made halocarbons have a considerable impact on the environment. Chlorine- and brominecontaining organic compounds such as chlorofluorocarbons (CFCs) and hydrochlorofluorocarbons (HCFCs) are responsible for the decline of stratospheric ozone and their use has therefore been regulated in the Montreal Protocol. Fluoro-containing halocarbons are not regulated within this treaty, but as all halocarbons act as greenhouse gases, this group of compounds was included in the Kyoto Protocol. Halogenated ozone destroying CFCs and chlorinated solvents were continuously measured in Switzerland at a suburban site near Zürich (Dübendorf) from 1994 until 2000 and since 2000 at the high alpine site of Jungfraujoch together with all greenhouse-active halocarbons. Furthermore, all anthropogenic halocarbons were measured in a campaign in Dübendorf in 2002. The analysis of the measurements confirms that a substantial decline of their emissions took place as a consequence of the Montreal Protocol. On the other hand, the concentration of substitutes such as hydrofluorocarbons (HFCs) increased dramatically. Linking continuously measured time series with meteorological information allows an estimation of regional emissions of the regulated compounds for Switzerland. In contrast to trade survey statistics or inventories, this method is an efficient tool to track the development of diffusive emissions of substances in long term usage such as foams and refrigerant systems.
\end{abstract}

Keywords: Atmospheric halocarbons · CFC · Emission estimation · GCMS · Montreal Protocol

\section{Introduction}

Man-made halogenated compounds are often used in industrial processes, consumer convenience products or building materials [1]. Most of these substances end up in the atmosphere, where many of them persist for a very long period of time, often for decades or even centuries. They have a considerable effect on the atmosphere and the environment, particularly with regard to ozone-depletion and global warming. Table 1 provides an overview of the main classes of such compounds, their residence time in the atmosphere and their main applications.

${ }^{*}$ Correspondence: Dr. B. Buchmann

Swiss Federal Laboratories for Materials Testing and Research (EMPA)

Air Pollution/Environmental Technology Laboratory Überlandstr. 129

$\mathrm{CH}-8600$ Dübendorf

Tel.: +4118235511

Fax: + 4118216244

E-Mail: brigitte.buchmann@empa.ch

www.empa.ch
The anthropogenic depletion of the stratospheric ozone layer is caused by a group of halocarbons containing chlorine and bromine atoms. These are chlorofluorocarbons (CFCs), hydrochlorofluorocarbons (HCFCs), halons (inert bromine-containing compounds), and two stable chlorinated solvents $\left(\mathrm{CH}_{3} \mathrm{CCl}_{3}\right.$ and $\left.\mathrm{CCl}_{4}\right)$. Two international treaties for the protection of the ozone layer, the Vienna Convention and the Montreal Protocol, were negotiated under the aegis of the United Nations Environment Programme (UNEP) and signed in 1985 and in 1987, respectively. The Montreal Protocol, which was put in force in 1989, covers all ozone layer depleting compounds. Developed countries being parties to the Protocol had to reach zero production for the home market by the year 1996 for the $\mathrm{CFCs}, \mathrm{CH}_{3} \mathrm{CCl}_{3}$ and $\mathrm{CCl}_{4}$, while a world-wide ban is scheduled for 2010 .

All of these substances also contribute to global warming [2]. The remaining halogenated greenhouse gases, which are not controlled by the Montreal Protocol, are covered by the Kyoto Protocol (1997) adopted under the United Nations Framework Convention on Climate Change (UNFCCC).

In Switzerland, measures to protect the ozone layer make-up part of the ordinance relating to environmentally hazardous substances [3]. In a first step, CFCs were prohibited as propellants in aerosol sprays (1991) as well as blowing agents for plastic insulation foams (1994). Installations of new devices using CFCs as refrigerants have been prohibited since 1994, the use of older CFC-containing devices, however, is allowed until 2004. The use of ozone depleting solvents has been forbidden since 1993, but many exceptions for specific industries were allowed until 1996. Switzerland has ratified the Kyoto Protocol in 2003 and the authorities have adapted the measures to survey, control and reduce emissions of atmospherically persistent HFCs, PFCs and $\mathrm{SF}_{6}$ in the recent modification of 
Table 1. Residence time of halogenated organic compounds in the atmosphere, examples and main applications

\begin{tabular}{|c|c|c|c|c|}
\hline & Classes of compounds & $\begin{array}{l}\text { Residence } \\
\text { in years [2] }\end{array}$ & $\begin{array}{l}\text { Example } \\
\text { this paper }\end{array}$ & Main applications \\
\hline $\begin{array}{l}\mathrm{M} \\
\mathrm{O}\end{array}$ & CFCs (chlorofluorocarbons) & $45-1700$ & $\begin{array}{l}\text { CFC } 11 \\
\text { CFC } 12 \\
\text { CFC } 113\end{array}$ & $\begin{array}{l}\text { foam blowing, propellant } \\
\text { refrigerant, propellant } \\
\text { solvent }\end{array}$ \\
\hline $\begin{array}{l}\mathrm{N} \\
\mathrm{T}\end{array}$ & HCFCs (hydrochlorofluorocarbons) & $10-20$ & HCFC 141b & foam blowing, solvent \\
\hline $\begin{array}{l}R \\
E\end{array}$ & Chlorinated hydrocarbons (solvents) & $4.8-30$ & $\begin{array}{l}\mathrm{CH}_{3} \mathrm{CCl}_{3} \\
\mathrm{CCl}_{4}\end{array}$ & $\begin{array}{l}\text { solvent } \\
\text { solvent }\end{array}$ \\
\hline $\begin{array}{l}A \\
L\end{array}$ & $\begin{array}{l}\text { Halons (bromine containing } \\
\text { halocarbons) }\end{array}$ & $10-60$ & & fire extinguishing agents \\
\hline $\begin{array}{l}K \\
Y \\
O\end{array}$ & HFCs (hydrofluorocarbons) & $1-300$ & $\begin{array}{l}\text { HFC } 152 a \\
\text { HFC } 134 a \\
\text { HFC } 125\end{array}$ & $\begin{array}{l}\text { foam blowing } \\
\text { refrigerant } \\
\text { refrigerant }\end{array}$ \\
\hline $\begin{array}{l}\mathrm{T} \\
\mathrm{O}\end{array}$ & $\begin{array}{l}\text { PFCs (perfluorocarbons), } \\
\text { SF }_{6}\end{array}$ & $3000-50 ’ 000$ & & $\begin{array}{l}\text { semiconductor industry } \\
\text { insulator }\end{array}$ \\
\hline
\end{tabular}

in the ordinance relating to environmentally hazardous substances dated July 2003 [3].

In order to observe the compliance of the Montreal treaty different methods (Fig. 1) the following can be considered:

a) Trade statistics (Table 2), collected by the Swiss Agency for the Environment, Forests and Landscape (SAEFL),

b) Emission estimations, derived from time series of continuous ambient air measurements at selected sites (regional, background).

The verification of existing inventories by complementary methods is of fundamental importance for air pollution control politics and allows criteria to be defined for the future surveillance of emissions in Europe.

This paper gives an overview of the measurement technique needed to analyse trace gas concentrations in the ppt (part per trillion) range and will discuss method $b$ ) in detail. Time series of continuous real time measurements at two different sites are presented and discussed with respect to international treaties:

1) Dübendorf, a suburban site close to Zürich (the largest town of Switzerland), representing the impact of regional emissions

2) Jungfraujoch, a high alpine station (3580 $\mathrm{m}$ asl), representative for European emissions [4].

Pollutants are influenced by the meteorological conditions of the atmosphere, thus showing daily variations according to changes in radiation, temperature, height of mixing layer or varying and weather dependent transport of air mass. Therefore,

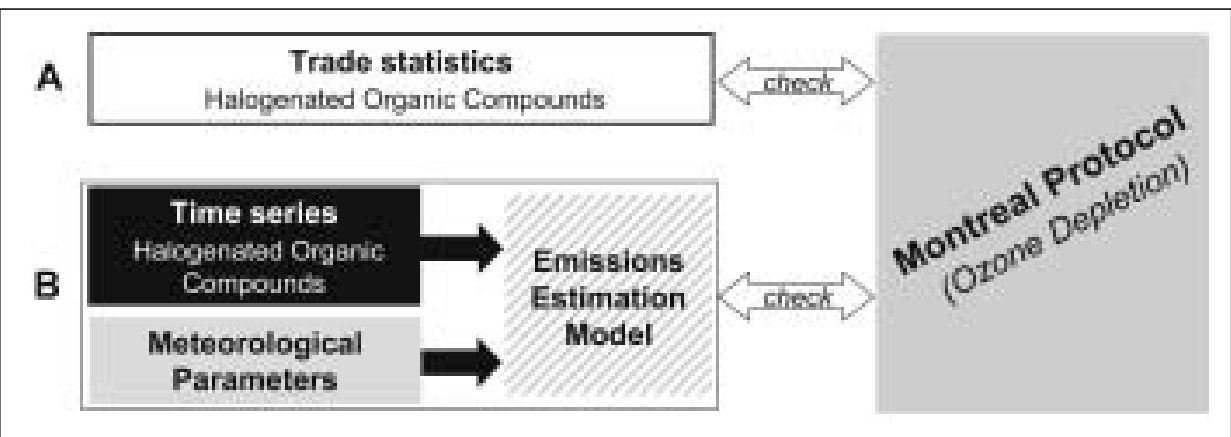

Fig. 1. Assessment of the Montreal Protocol: A) Trade statistics, B) Time series in combination with emission models

Table 2. Swiss import statistics ${ }^{a}$ of ozone layer depleting compounds: a surveillance tool to verify compliance with the Montreal Protocol.

\begin{tabular}{|c|c|c|c|c|}
\hline & $\begin{array}{l}\text { CFCs for plastic } \\
\text { foam blowing } \\
\text { [tons] }\end{array}$ & $\begin{array}{l}\text { CFCs as } \\
\text { refrigerants } \\
\text { [tons] }\end{array}$ & $\begin{array}{l}\text { CFCs as } \\
\text { solvents } \\
\text { [tons] }\end{array}$ & $\begin{array}{c}\mathrm{CH}_{3} \mathrm{CCl}_{3} \\
\text { [tons] }\end{array}$ \\
\hline 1986 & 2489 & 444 & 1760 & - \\
\hline 1989 & 2853 & 404 & 910 & 3484 \\
\hline 1990 & 1346 & 459 & 1155 & - \\
\hline 1991 & 645 & 483 & 1236 & 2510 \\
\hline 1992 & 101 & 459 & 1212 & 2314 \\
\hline 1993 & 80 & 514 & 818 & 1458 \\
\hline 1994 & 29 & 436 & 390 & 748 \\
\hline 1995 & 0 & 170 & 142 & 250 \\
\hline 1996 & 0 & 5 & 0 & 37 \\
\hline 1997 & 0 & 14 & 0 & 0.8 \\
\hline 1998 & 0 & 31 & 0 & 1.6 \\
\hline 1999 & 0 & 76 & 0 & 1.7 \\
\hline 2000 & 0 & 45 & 0 & 0.6 \\
\hline
\end{tabular}

a the import statistic by the Swiss Agency for the Environment, Forests and Landscape, ${ }^{b}$ mainly CFC $11,{ }^{c}$ mainly CFC $12,{ }^{d}$ mainly CFC 113 
estimations of the emissions of halogenated compounds in direct relation to ambient air measurements can be obtained by various methods such as trajectory statistics [5][6] or by using the mixing layer height under well-selected conditions, as demonstrated in this work.

\section{Experimental}

\section{Measurement Sites}

Two measurement sites were selected for this investigation, representing different types of emission regions:

- Dübendorf is a small town located in the agglomeration of Zürich. The region is densely populated, has a broad mix of different industrial-, research-, waste disposal, and military facilities and many roads and highways with dense traffic. A variety of different emission sources can therefore be expected to contribute to the local air pollution.

- The high-Alpine site of Jungfraujoch is situated in the northern part of the Swiss Alps forming the first topographical barrier to the frequent westerly and northerly winds in Central Europe. The site is situated on a prominent rock formation at the saddle between the summits of Jungfrau (4158 $\mathrm{m}$ asl) and Moench (4099 $\mathrm{m}$ asl). The site is remotely located for Central European conditions, with the small towns of Grindelwald and Wengen at $8 \mathrm{~km}$ horizontal and $2.5 \mathrm{~km}$ vertical distance. Due to its elevated and remote location the Jungfraujoch station is only slightly influenced by local anthropogenic sources and therefore represents background conditions in most cases. Apart from a few local events, only larger scale source regions such as Central Europe [7] have a measurable impact on the composition of the air at Jungfraujoch.

\section{Measurement Techniques}

Many of the halogenated compounds mentioned above are found at very low concentration levels of a few parts per trillion and hence require well-designed trace analytical methods for their analysis. In addition, changes of the regulations with respect to the consumption of the halocarbons had a strong influence on the development of the analytical measurement technique towards lower detection limits. In the course of the reduction of the CFCs, peak concentrations caused by singular emission events are more and more difficult to distinguish from background concentrations, and require higher analytical precision. Furthermore, the introduction of CFC replacement compounds (like HFCs, HCFCs and PFCs) requires a more versatile analytical method.
The measurements in Dübendorf from 1994 until 2000 were performed with a sampling interval of one hour. The compounds were extracted onto a $1 / 8$ inch o.d. trap, filled with $20 \mathrm{~cm}$ of Tenax TA followed by $10 \mathrm{~cm}$ of Carbosieve S-III. During sampling, the trap was cooled to $-10{ }^{\circ} \mathrm{C}$ by $\mathrm{CO}_{2}$ and subsequently heated to $145^{\circ} \mathrm{C}$ in order to release the trapped compounds. The compounds were flushed by the carrier gas into the gas chromatograph (Varian 3400), where separation was performed on a capillary column (Restek 502.2, $0.53 \mathrm{~mm}$ $\times 105 \mathrm{~m}$ ) followed by electron capture detection (ECD).

The new system developed for the continuous measurements at the Jungfraujoch station has to deal with the low concentrations of the CFC-substitutes, which are usually one or two orders of magnitude smaller than the CFC concentrations. A new detection system had to be introduced, as the sensitivity of the ECD detector was no longer sufficient to analyse these compounds, because the substitutes contain considerably less chlorine and bromine and occur at much lower concentrations.

The new system consisted of a microtrap (Adsorption Desorption System, ADS), [8] connected to a gas chromatograph-mass spectrometer (GCMS). A sample volume of two litres of air was concentrated onto the trap, which was cooled to $-50{ }^{\circ} \mathrm{C}$ by a Peltier element. Subsequently, halocarbons were desorbed by fast inductive heating of the micro-trap at $235^{\circ} \mathrm{C}$ and were transferred into the gas chromatograph through an uncoated silanised fused silica capillary without further cryofocussing. A capillary column $(0.32 \mathrm{~mm} \times$ $120 \mathrm{~m}$ CP-SIL 5CB, Chrompack) with film thickness of $5 \mu \mathrm{m}$ was used for separation. The temperature programme started at $37{ }^{\circ} \mathrm{C}$ and reached $180{ }^{\circ} \mathrm{C}$ within $51 \mathrm{~min}$. The individual compounds were quantified by single ion mass spectrometry of selected characteristic ions in combination with their individual chromatographic retention times.

\section{Model to Estimate Emissions for Switzerland}

At the suburban site Dübendorf, during stable high-pressure conditions in summer, concentrations of chlorofluorocarbons (CFCs), 1,1,1-trichloroethane $\left(\mathrm{CH}_{3} \mathrm{CCl}_{3}\right)$, and tetrachloromethane $\left(\mathrm{CCl}_{4}\right)$ exhibit a diurnal cycle (Fig. 2). Daytime concentrations are generally lower than during the night. This pattern is inversely reflected by the height of the boundary layer, which, at given meteorological conditions, is very low at night and high during the day. The higher nightly concentrations are caused by emissions into the very low boundary layer during this period.

In this study regional emissions of the halocarbons have been assessed by combining their increase during the night with information about the night-time boundary layer height. By standardising these emissions per area with the population density, emission estimates for Switzerland were derived.

The boundary layer parameters, necessary to determine night-time boundary layer height were calculated with a meteorological pre-processor, which was developed by Hanna and Chang. [9]. The height of the boundary layer is calculated using the equation suggested by Nieuwstadt [10], where $h$ is a function of the Obukhov length, the

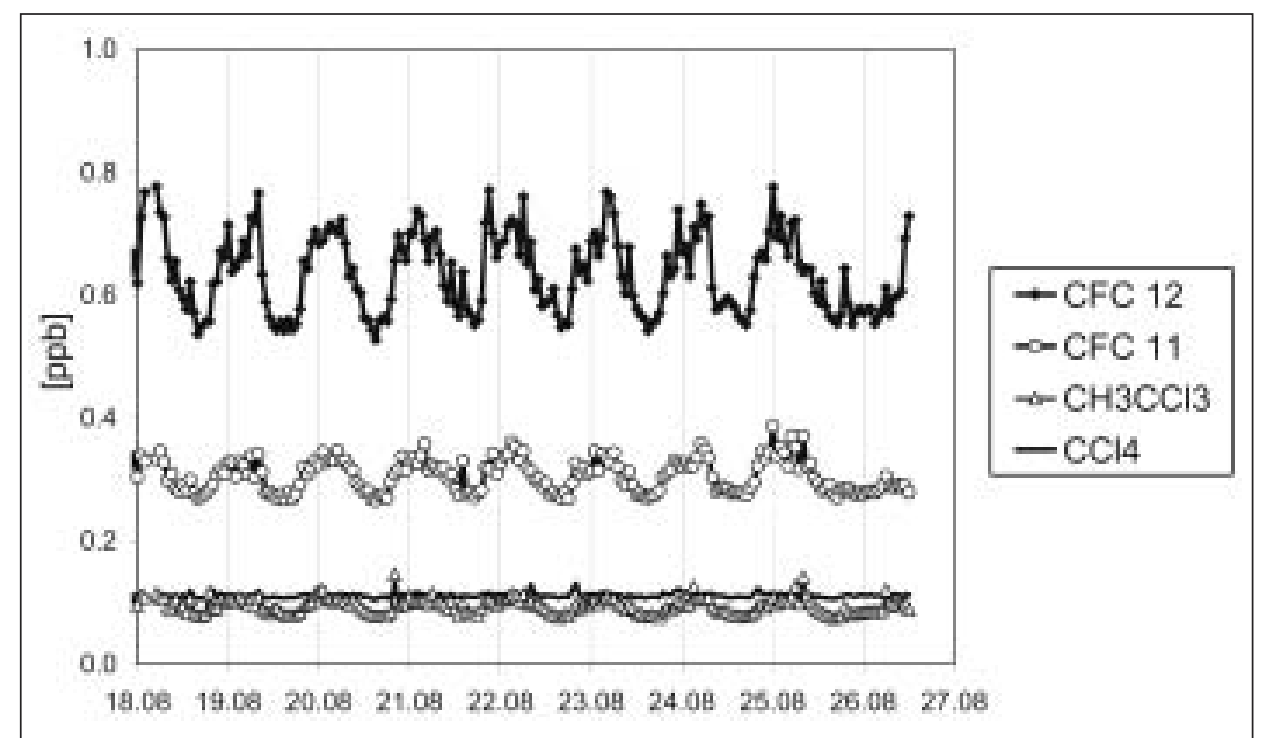

Fig. 2. Daily cycles of different chlorofluorocarbons (CFCs) and of the chlorinated solvents trichloroethane $\left(\mathrm{CH}_{3} \mathrm{CCl}_{3}\right)$ and tetrachloromethane $\left(\mathrm{CCl}_{4}\right)$ during a stable warm weather period in summer 1997 in Dübendorf. 
friction velocity and the Coriolis parameter. Using this data an averaged night-time boundary layer height of $30 \mathrm{~m}$ was estimated above the measurement site of Dübendorf during stable summer conditions with low wind speed $\left(<1 \mathrm{~ms}^{-1}\right)$.

We assumed that the source strength has no diurnal variation and that the increase of the concentrations is linear during the first part of the night. The hourly increase rates of the substances during this time of the day were used to estimate the emissions into a box. Extrapolating the hourly emissions to annual emission and dividing them through the population density at the site (1543 inhabitants $/ \mathrm{km}^{2}$ ), gives a reasonable estimation of the emission of individual substances in $g$ per head per year. Assuming that the mix of industries, agriculture and housing areas around the measurement site of Dübendorf is representative for Swiss conditions, the emission estimates can be extended to all of Switzerland. The following analysis of the representativeness of the Dübendorf site demonstrates the validity of our assumption.

\section{Representativeness \\ of the Time Series}

Observations at a single site such as Dübendorf, located in a densely populated area may be excessively influenced by specific regional and local sources and cannot a priori be regarded as representative. For this reason the relative contribution of different halogenated organic compounds was analysed at four different sites in Switzerland.

The analysis included data of the Dübendorf site, the continuous monitoring programme at Jungfraujoch and short-term measurement campaigns of a few months in 2002 with the GCMS-method at two additional sites, Zürich and Rigi. The Zürich site represents a city background in a densely populated area with similar site characteristic as Dübendorf, whereas Rigi is an elevated site on the slope (Rigi-Seebodenalp, $1030 \mathrm{~m}$ asl) of the mountain Rigi. This site is exposed towards the populated Swiss plateau, not affected by local sources of anthropogenic halocarbons, but by integral emissions from the Swiss plateau. The analytical method included about 20 halogenated organic species, representing the most important halogenated compounds used in different industrial applications. For each compound the relative fraction above the background with respect to total halocarbon concentration was calculated (Fig. 3 ). These figures allow comparing relative concentrations of the compounds from different geographical source regions. The relative composition shows a good agreement

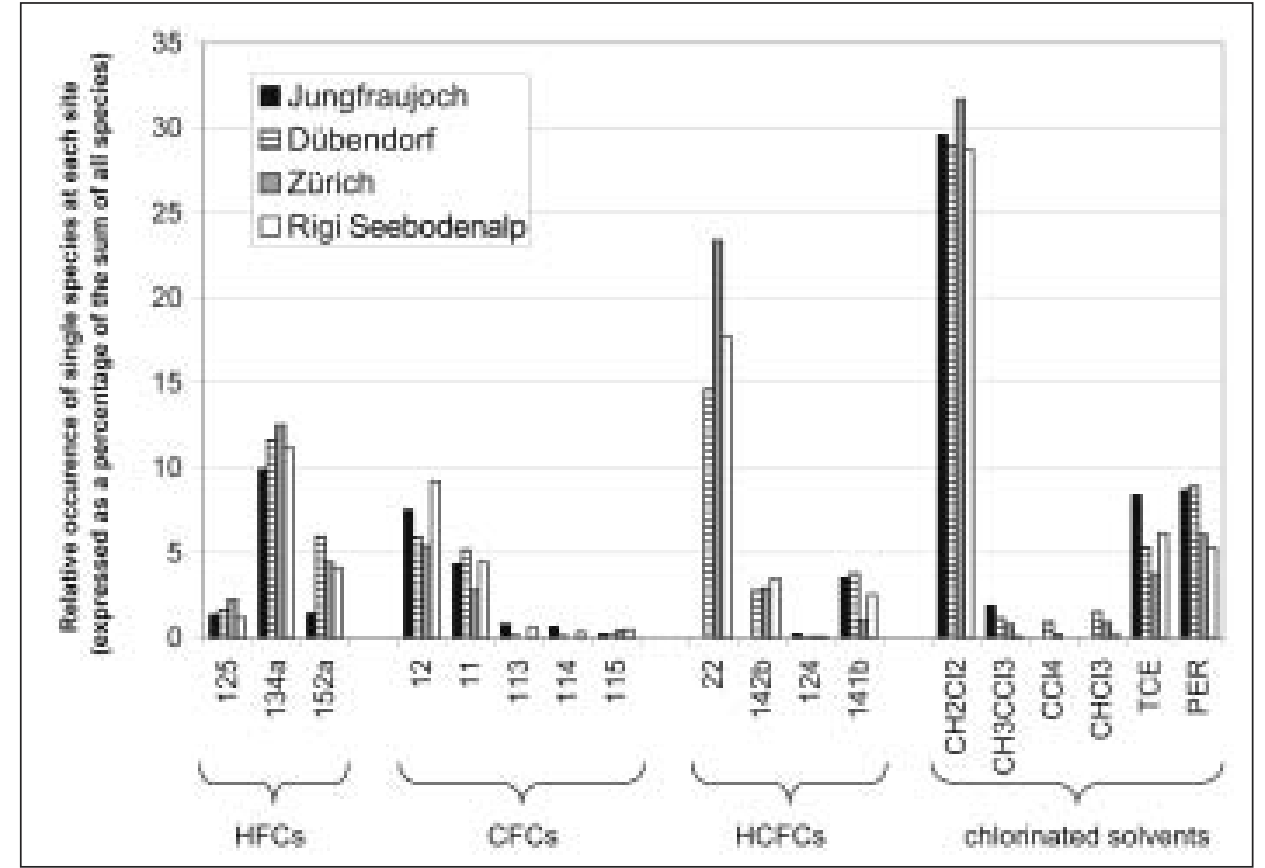

Fig. 3. Relative strength of the emissions of important anthropogenic halocarbons as observed: in Zürich city centre (May-June2002) ( $\square$ ), in Dübendorf (Feb-April 2002) (巨), at Rigi See-

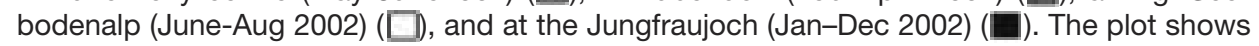
the fraction of each species as a percentage of the sum of all species at a specific site. HCFC 22 and HCFC 142b were not included in the totals as they were not measured at the Jungfraujoch.

for all compounds at each site (except for HFC 152a at Jungfraujoch, which has a dominant source in the north [7]). This demonstrates that even in industrialised and heavily populated areas (Dübendorf) source region observations are quite representative and the observed emissions of halogenated compounds can be judged as typical for Switzerland.

\section{Results and Discussion}

\section{Montreal Protocol Measures Reflected by the Time Series}

A few examples of time series from Dübendorf representing different classes of compounds with different industrial applications were chosen to demonstrate the effectiveness of measures which have been taken to reduce the regulated compounds (Fig. 4).

A distinct decay of the ambient air concentration for $\mathrm{CH}_{3} \mathrm{CCl}_{3}$ (Fig. 4A) was observed at this suburban site. Pollution events with mixing ratios exceeding several $100 \mathrm{ppt}$ were frequently monitored in 1994, becoming sparse towards 1999. In addition, not only the maximal and mean concentrations of $\mathrm{CH}_{3} \mathrm{CCl}_{3}$, but also the lowest observed concentrations decreased during the same period. Such low concentrations are observed during unpolluted sit- uations and represent the tropospheric background [11]. The measurements from 2000-2003 at the Jungfraujoch site (Fig. 4, grey line), hardly affected by regional emissions and therefore reflecting the decay of the tropospheric background concentration in a direct way, are very well in line with the unpolluted (lower envelope line) Dübendorf measurements for the years 1994-1999. This decay $(\mathrm{k}=0.199 \pm 0.002$ $\mathrm{yr}^{-1}$ ) can be attributed mainly to oxidation of $\mathrm{CH}_{3} \mathrm{CCl}_{3}$ in the troposphere [12].

For CFC 113, with an estimated atmospheric life-time of 85 years [2], the tropospheric background concentration observed, at global background monitoring sites, shows no significant decay during the last 10 years. However, the regional concentrations recorded in Dübendorf (Fig. 4B), decayed in a very similar way as seen for $\mathrm{CH}_{3} \mathrm{CCl}_{3}$. This can be explained by the fact that both $\mathrm{CH}_{3} \mathrm{CCl}_{3}$ and $\mathrm{CFC} 113$ were predominantly used as solvents. In 2002 local emissions of CFC 113 were hardly detected during the measurement period in Dübendorf, in accordance with Swiss regulations prohibiting its use in the 1990s.

Comparison of trade statistics (Table 2) and measurements of regional emissions at the Dübendorf site (Fig. 5) for $\mathrm{CH}_{3} \mathrm{CCl}_{3}$ and CFC 113 shows a close correlation, i.e. a dramatic decrease between 1994 and 1997. The immediate impact of the regula- 


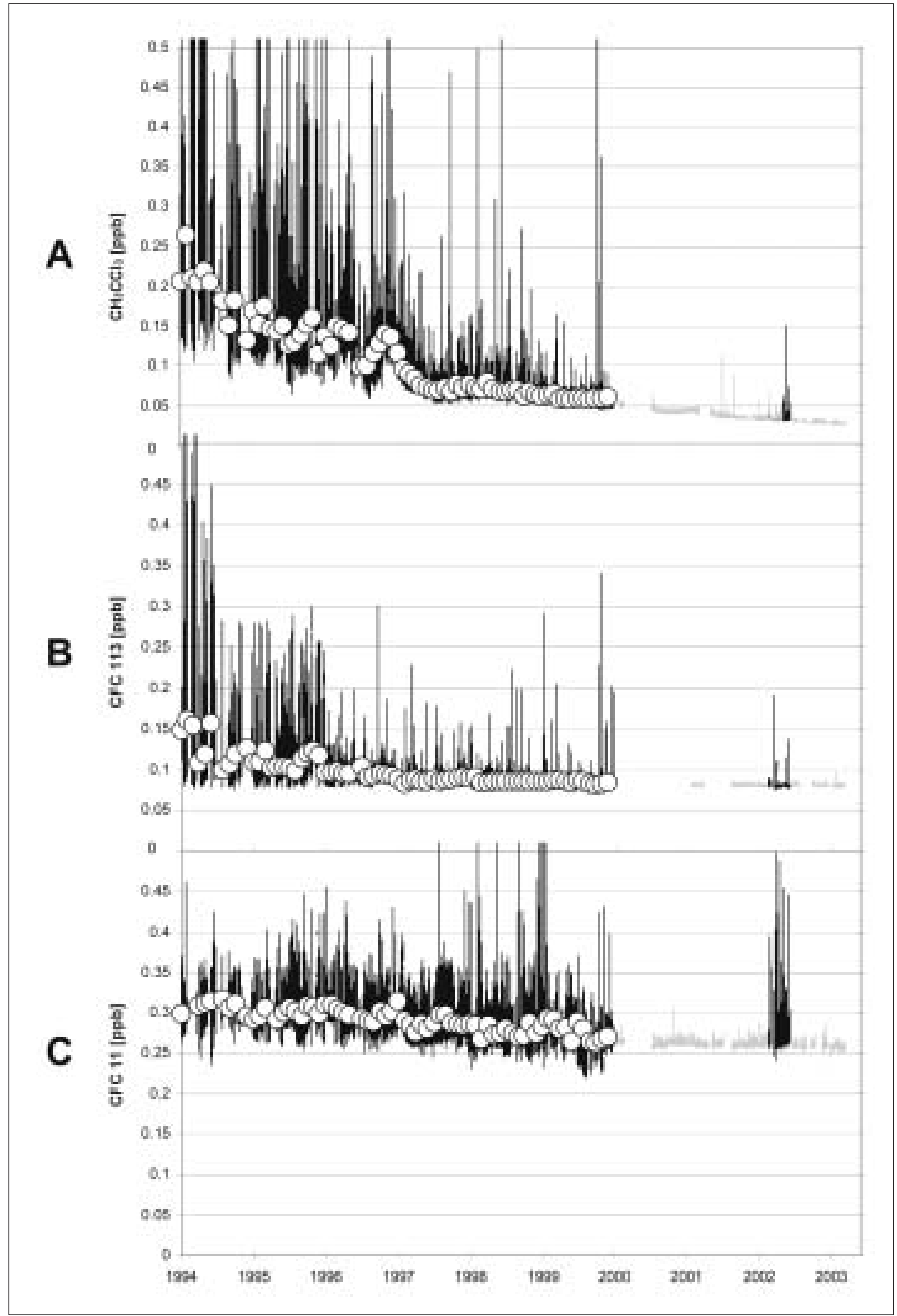

tions on the emission of $\mathrm{CH}_{3} \mathrm{CCl}_{3}$ and $\mathrm{CFC}$ 113 is easy to understand as these compounds were mainly used as solvents, an application with a short banking time of 1-2 years [1][13][14].

CFC 11 is another stable compound with an estimated atmospheric life-time of 45 years [2]. As a consequence, the measured background concentrations decrease only to a very small extent. Data from Dübendorf (Fig. 4C) show that regional emission events have also been decaying slowly since 1994 . However, the measurement period in 2002 still shows major peak events. They must be caused by local emis-

sion sources since peak events do not occur in the Jungfraujoch data series of CFC 11 (Fig. 4C; grey line). Peak values are often not correlated with other pollutants, a fact that may indicate a single industrial point source, still emitting CFC 11.

In order to clarify the development mentioned above, the tropospheric background concentration of the Northern Hemisphere [7] is subtracted from the monthly mean concentrations at Dübendorf (Fig. 5). The concentrations of CFC 113 and $\mathrm{CH}_{3} \mathrm{CCl}_{3}$ have approximately reached the global background concentration, while the measurements at the Dübendorf site still
Fig. 4. Measured mole fractions of $\mathrm{CH}_{3} \mathrm{CCl}_{3}$ (A), CFC 113 (B) and CFC 11 (C) in Dübendorf, Switzerland (1994-1999 and 2002) (black line) and at Jungfraujoch, Switzerland (2000-2003) (grey line). Monthly mean values of the measured mole fractions (open circles).

indicate emissions of CFC 11 in Switzerland.

The different situation for CFC 11 appears reasonable due to its use in foam blowing processes and propellants. Imports of CFCs as foam blowing agents (Table 2) decreased exponentially from 1990 until 1995, when no more imports were registered. In contrast to the import statistics, ambient air concentrations above background dropped much slower from 1994 to 1998 , i.e. only by a factor of $2-3$. Data from 1998 until 1999 and the short measuring period in 2002 show no further decay. The reason for this slower decay of the concentration of CFC 11 is due to the different applications of CFC 11: e.g. as aerosol propellant, blowing agents for open and closed cell foams and - to a minor degree - cooling agent, all having different retention times [14][15]. The longest retention time is assumed for closed cell blowing, particularly in polyurethane foams, historically a very important application of CFC 11 . The initial decay (1994-1998) of the concentrations observed in Dübendorf, is much faster than calculated by McCulloch et al. [15] in their global survey for closed cell foam products. This makes it very likely that the effect was due to applications with shorter banking times, while the stagnation since 1998 indicates a domination of closed cell foam products, for which McCulloch et al. [15] estimates a long time constant for the emission in the order of 20 years.

\section{Occurrence of CFC}

Substitutes as a Consequence of the Regulations

After the ban of CFC 11, the industry developed several substitutes and alternative technologies to satisfy the demand for insulation foam blowing. The first action was to substitute the fully halogenated CFCs by hydrochlorofluorocarbons (HCFCs). These compounds are judged as environmentally less problematic than CFCs because they are significantly less persistent in the atmosphere and do not reach the stratospheric ozone layer to the 


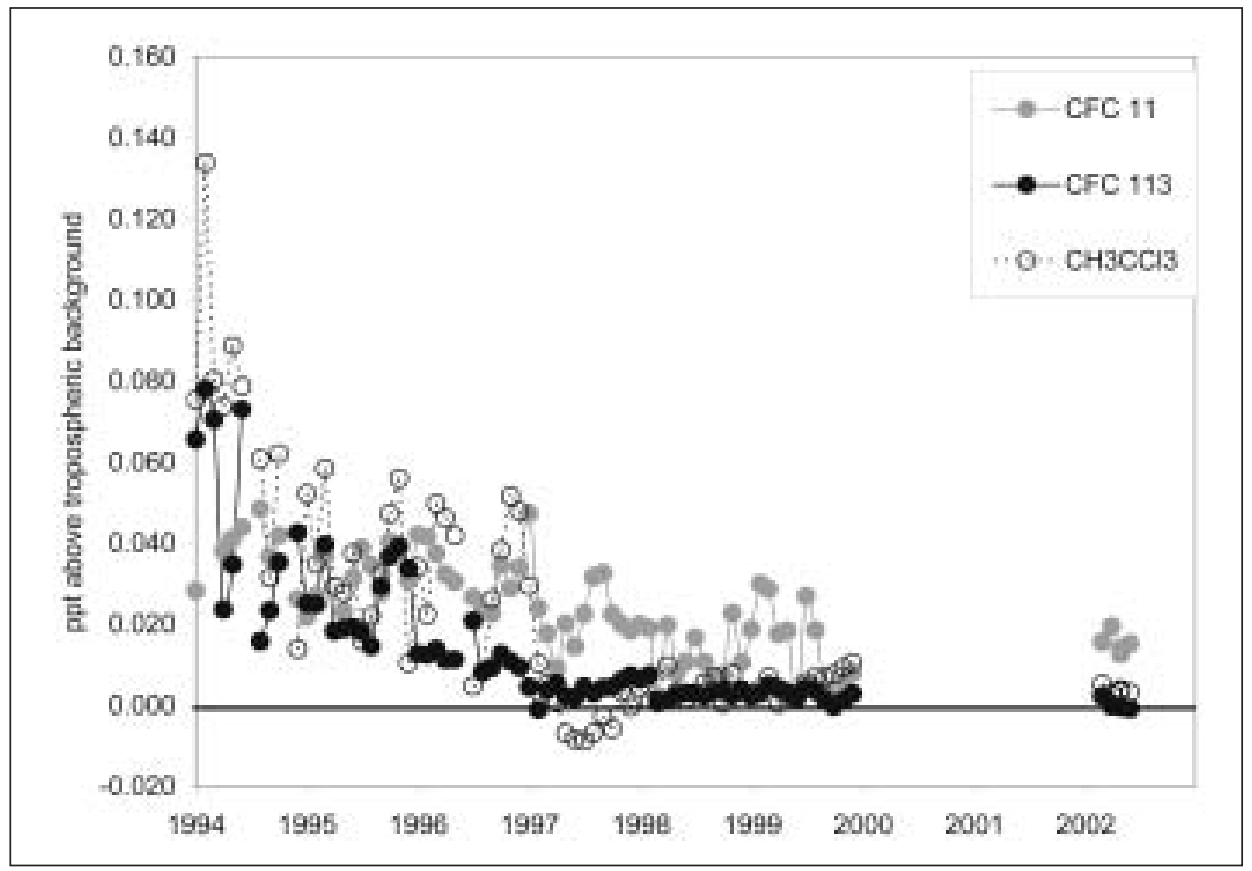

Fig. 5. Monthly mean values of $\mathrm{CH}_{3} \mathrm{CCl}_{3}$, $\mathrm{CFC}$ 113 and CFC 11 in Dübendorf, Switzerland above the background mixing ratio of the troposphere (northern hemisphere) derived from the global background measuring site at Mace Head, Ireland [11].

same extent as the CFCs. However, because the HCFCs still contain chlorine, they are only regarded as interim substitution products and their use in foam blowing applications was already prohibited in Switzerland in 2000. The HCFCs will continuously be replaced by a second generation of substitutes. For foam blowing applications the HCFCs will be replaced by HFCs, containing only fluorine as halogen, therefore being harmless with regard to ozone depletion but still acting as greenhouse gases. Time series of the substitutes HCFC 141b (first generation), and HFC 152a (second generation) are compared with the banned CFC 11 (Fig. 6). Due to its large historic production, CFC 11 has accumulated to a level of about $260 \mathrm{ppt}$ and only recently shows a slight decay of $0.5 \%$ per year. The HCFC $141 \mathrm{~b}$ levels are still increasing by about 1 ppt per year. Today, the frequency and magnitude of pollution events from CFC 11 and HCFC 141b, as monitored at the Jungfraujoch, are nearly identical, which lets us assume that Central European emissions are in the same order of magnitude for both compounds. For the time being HFC 152a shows low emissions, but a substantial growth of pollution episodes was monitored during the last three years at the Jungfraujoch, indicating its increasing use as foam propellant.

\section{Swiss Emissions Derived} From Ambient Air Measurements

Time series from 1994 to 1999 and 2002, measured at the Dübendorf site, are used to estimate Swiss emissions by applying the model described above. The model

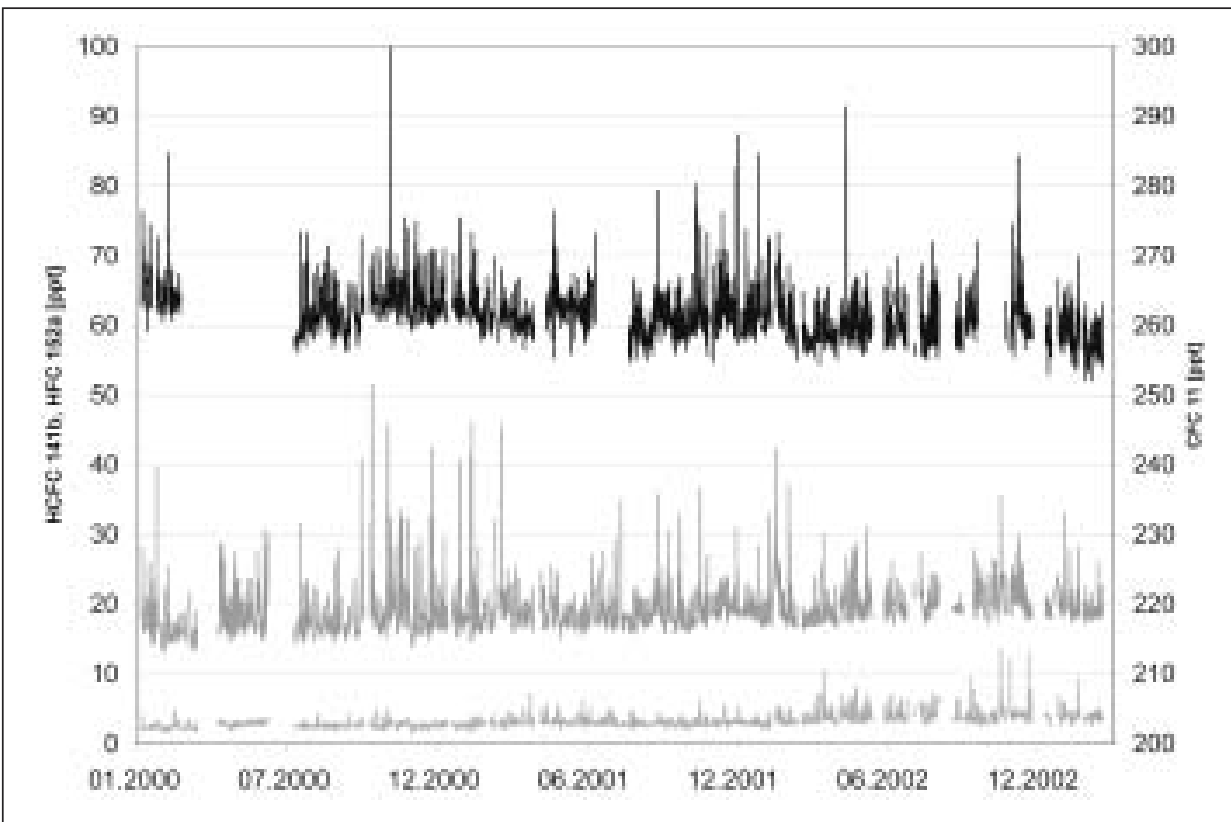

Fig. 6. Data series of three halogenated trace gases, predominantly used for polyurethane insulation foam blowing, Jungfraujoch (January 2000 to March 2003): (top) CFC 11, (middle) HCFC 141b, and (bottom) HFC 152a.

estimation shows the largest decay of about $98 \%$ for the solvent $\mathrm{CH}_{3} \mathrm{CCl}_{3}$. The $\mathrm{CFC}$ emissions have declined as well, although to a lesser extent, i.e. $85 \%$ for CFC 12 and $82 \%$ for CFC 11 since 1993 (Fig. 7).

For 1995, in contrast to the model estimation, the Swiss import statistics for ozone layer depleting compounds show zero emission for CFC 11, as the import of CFCs for foam blowing applications has been forbidden since 1994. This example demonstrates the advantage of determining emissions with a model based on ambient air measurements. Thus, the banking of ozone depleting compounds in materials such as foams are automatically included in the emission estimation derived from measurements. In addition, our model allows an estimation of emissions for the HFCs (Fig. 7), relevant for the Kyoto Protocol. The calculated emission rates of the ozone depleting CFCs (CFC 11, CFC 12) in the year 2002 are in the same order of magnitude as the rates calculated for their substitutes (HFC 125, HFC 134a and HFC 152a). 


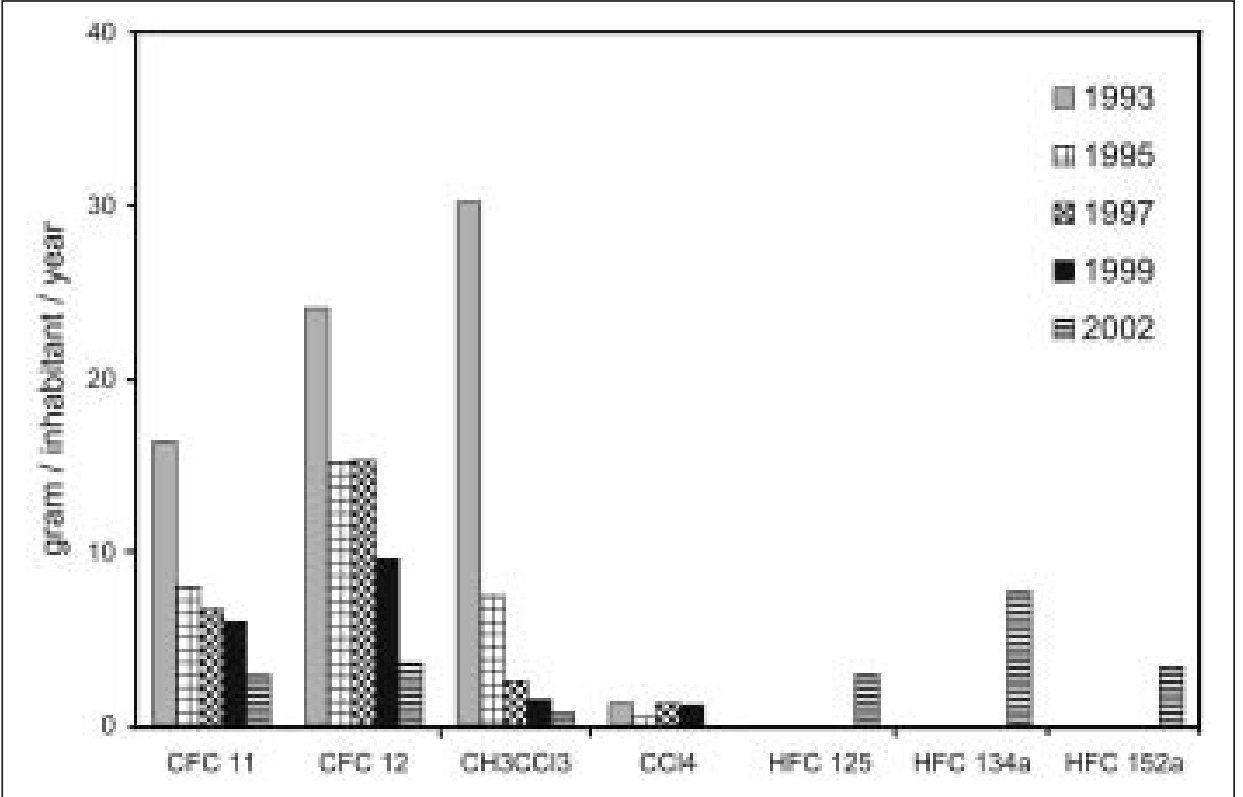

Fig. 7. Regional emission estimates of chlorofluorocarbons (CFCs), chlorinated solvents 1,1,1trichloroethane $\left(\mathrm{CH}_{3} \mathrm{CCl}_{3}\right)$ and tetrachloromethane $\left(\mathrm{CCl}_{4}\right)$ for the period of 1993-2002 derived from ambient air measurements in Dübendorf. For 2002, regional emission estimates of Dübendorf for chlorofluorocarbons (CFCs) are compared with their subsitutes HFCs 125, 134a and $152 a$.

New compounds introduced by industry, but not yet declared, can also be measured and identified by our technique. Emission rates for new compounds may therefore be calculated long before they are found in trade statistics.

\section{Conclusions}

Ambient air measurements combined with atmospheric information allow the investigation of the effect of the measures taken to reduce halogenated hydrocarbons in an independent way. Time series of longterm measurements demonstrate a significant decrease of regulated halocarbons containing chlorine and bromine. Comparing the behaviour of the different compounds under discussion clearly indicates that their decay is influenced by the residence time in the atmosphere as well as by the banking time, specific for their individual application. Halogenated hydrocarbons used as solvents (e.g. $\mathrm{CH}_{3} \mathrm{CCl}_{3}$ ) are immediately emitted into the atmosphere, while important foam blowing agents like CFC 11 have delayed emissions. Compounds used as substitutes for banned components show a strong increase. Future activities will therefore include investigations into known substitutes but will also pay attention to new compounds designed as replacements. Our measurement method allows to detect new compounds already at a very early stage, even before they appear as official trademarks or in trade statistics.

\section{Acknowledgements}

We gratefully acknowledge the financial support of this work by the Swiss Federal Office of Environment, Forests and Landscape (BUWAL). We thank MeteoSwiss for providing meteorological data. Our thanks also go to P. Calanca (FAL Zürich) for helpful discussions. We acknowledge the International Foundation 'High Altitude Research Station Jungfraujoch and Gornergrat (HFSJG)' for making research possible at their High Altitude Research Station.

Received: July 5, 2003

[1] P.M. Midgley, A. McCulloch, 'Properties and Applications of Industrial Hydrocarbons', in 'The Handbook of Environmental Chemistry', Vol. 4E: Reactive Halogen Compounds in the Atmosphere', Eds.: P. Fabian, O.N. Singh, Springer-Verlag, Heidelberg, 1999, p. 129-153, 155-190, 203-221.

[2] IPCC 'Climate Change 2001', Cambridge University Press, Cambridge, UK, 2001.

[3] Ordinance relating to Environmentally Hazardous Substances (Osubst; SR 814.013), Stoffverordung (StoV; SR 814.013), 9. Juni 1986 (update 1. Juli 2003).

[4] S. Reimann, D. Schaub, K. Stemmler, A. Weiss, P. Hofer, B. Buchmann, P.G. Simmonds, B. Greally, S. O'Doherty, Atmos. Environ., submitted 2003.

[5] P. Seibert, H. Kromp-Kolb, U. Baltensperger, D.T. Jost, M. Schwikowski, A. Kasper, H. Puxbaum, 'Trajectory Analysis of Aerosol Measurements at High Alpine Sites, in Transport and Transformation of
Pollutants in the Troposphere', Eds. P. M. Borrell et al., Academic Publishing, Den Haag. 1994, p. 689-693.

[6] S. Reimann, D. Schaub, K. Stemmler, A. Weiss, B. Buchmann, P. Hofer, 'Kontinuierliche Messungen auf dem Jungfraujoch HALCLIM', EMPA-Bericht-Nr. 201203. 2002.

[7] A. McCulloch, P.M. Midgley, P. Ashford, Atmos. Environ. 2003, 37, 889.

[8] P.G. Simmonds, S. O’Doherty, G. Nickless, G.A. Sturrock, R. Swaby, A. Knight, J. Ricketts, G. Woffendin, R. Smith, Analytical Chemistry 1995, 67(4), 717-723.

[9] S.R. Hanna, J.C. Chang, Atmos. Environ. 1993, 27A, 1491-1508.

[10] F.T.M. Nieuwstadt, Boundary-Layer Met. 1981, 20, 3-17.

[11] R.G. Prinn, R.F. Weiss, P.J. Fraser, P.G. Simmonds, D.M. Cunnold, F.N. Alyea, S O'Doherty, P. Salameh, B.R. Miller, J. Huang, R.H.J. Wang, D.E. Hartley, C. Harth, L.P. Steele, G. Sturrock, P.M. Midgley, A. McCulloch, J. Geophysical Research 2000, 105(D14), 17751.

[12] R.G. Prinn, J. Huang, R.F. Weiss, D.M. Cunnold, P.J. Fraser, P.G. Simmonds, A. McCulloch, C. Harth, P. Salameh, S. O'Dorherty, R.H.J. Wang, L. Porter, B.R. Miller, Science 2001, 292, 1882.

[13] A. McCulloch, P.M. Midgley, Atmos. Environ. 2001, 35, 5311.

[14] AFEAS (Alternative Fluorocarbons Environmental Acceptability Study), 'Production, sales and Atmospheric Release of fluorocarbons trough 2001' published at www.afeas.org by AFEAS, Arlington, Rand ES\&P Centra 1200 South Hayes St., Arlington VA, USA, 2001.

[15] A. McCulloch, P. Ashford, P.M. Midgley, Atmos. Environ. 2001, 35, 4387. 